\title{
THE VACCINE TREATMENT OF WHOOPING-COUGH
}

\author{
E. MATHER SILL, M.D.
}

Attending Physician Diseases of Children, Good Samaritan Dispensary; Lecturer Diseases of Children, New York Polyclinic Medical School and Hospital.

NEW YORK

The organism of whooping-cough has long been sought and many investigators have described it as an influenza-like bacterium. Notable among these workers was Spengler, ${ }^{1}$ who in $189 \%$, called attention to the organism so often found in pertussis sputum. Bordet ${ }^{2}$ of Brussels has described at length his work with the bacillus of whooping-cough which he discovered in 1905 .

It appears that the organism grows by choice low in the lung and rarely above the larynx. During the early stage of the disease it is found abundantly, but becomes more scanty as the disease progresses. Its culture artificially is slow and difficult, unless the tube is inoculated without other organisms. On account of its slow growth it is easily overgrown by pneumococci and influenza bacilli. The best medium according to Bordet is defibrinated blood, human or rabbit, mixed with an equal quantity of 3 per cent. agar, containing a little extract of potato or glycerin. Culturally on the above medium, in two to four days, it shows a fairly thick, whitish streak, the subjacent blood being hemolyzed but not blackened. This appearance is unlike that of bacteria morphologically similar, such as that of influenza. The organism grows, too, on serum-agar and in liquid media, such as serum-bouillon and bloodbouillon, provided shallow vessels be used so as to provide a large surface in contact with air, the bacterium being an obligatory aerobe.

Under the microscope, according to Bordet, the organism appears as a small cocco-bacillus, in size and shape comparable to the bacillus of influenza. Examined in original cultures, it is usually rather longer and plumper, but during the progress of subcultivation it becomes smaller until it finally appears as a mere point even under the highest powers. Bordet's bacillus is non-motile, negative to Gram, and stains feebly with the usual basic dyes, such as methylene or toluidin blue, but best by weak fuschin.

From Bordet's paper the following is extracted:

The ordinary laboratory animals seem to be but little if at all affected by the infection of this bacteria. An exception must be made in the case of monkeys. Klimenko and Fraenkel claim to have produced a

1. Spengler: Deutsch. med. Wchnschr., 1897, xxiii, 830 .

2. Bordet: Brit. Med. Jour., 1909, ii, 1062. 
real whooping-cough in these animals. In the rabbit and guinea-pig the bacillus is unable to invade the organism, when injected into skin or peritoneum. When, however, these animals are given a few milligrams of culture from solid media, in the peritoneum, they die with all the symptoms of profound toxemia without the development of a real infection. We may, therefore, conclude that the bacterium of whoopingcough is endowed with toxin-producing properties of a high order. By making use of the method introduced by Besredka we have, in fact, succeeded in extracting an endotoxin, a poison in the guise of a slightly opalescent liquid. In small doses, which represent only a most minute quantity of microbic matter, a fatal result ensues on its injection into a guinea-pig's peritoneum, with the production of the same hemorrhagic and exudative lesions which follow the injection of the living germ. Inoculated under the skin in the dose of 0.25 centigrams it induces a hemorrhagic edema followed by wide-spread necrosis, the skin becoming black, and on the separation of the slough it leares a vast ulcer of several square centimeters. An analogous necrosing influence has been seen clearly on the surface of the bronchi in affected children. Bordet, on account of these experiments, concludes that the cough in pertussis is due to the liberation of this toxin on the mucosa of the deeper respiratory tract.

The agglutination reaction is observed in using the serum of a pertussis patient. The highest dilution producing complete agglutination was 1 to 60 . This is significant in that agglutination did not occur when using non-pertussis serum in 1 to 4 and 1 to 8 . This agglutination reaction is, therefore, very strong evidence that Bordet's bacillus is the causative factor of pertussis.

\section{EXPERIMENTAL WORK}

The following experiments are of interest in connection with the use of pertussis vaccine. Dr. J. Freeman ${ }^{3}$ of London conducted an exceedingly well-controlled series of cases. The controls in this series received injections of sterile salt solution instead of the vaccine, and the results were as follows:

$\begin{array}{ccc}\text { Class. } & \text { Vaccine. } & \text { Controls. } \\ \text { Much better } \ldots \ldots \ldots \ldots \ldots \ldots & 31.0 & 21.55 \\ \text { Better } \ldots \ldots \ldots \ldots \ldots \ldots \ldots \ldots & \mathbf{3 7 . 1} & \mathbf{3 4 . 5 5} \\ \text { Unchanged } \ldots \ldots \ldots \ldots \ldots \ldots \ldots & \mathbf{1 5 .}+ & \mathbf{2 3 . 9} \\ \text { Worse } \ldots \ldots \ldots \ldots \ldots \ldots \ldots \ldots & 15.2 & 18.15 \\ \text { Much worse } \ldots \ldots \ldots \ldots \ldots \ldots & 1.0 & 1.85\end{array}$

His routine dose was five million; he then dropped to two and onehalf million, then rose to twenty million.

3. Freeman, J.: Brit. Med. Jour., 1909, ii, 1064. 
Pfaundler and Schlossman, in their work on children's diseases, give the average duration of pertussis in light uncomplicated cases as varying between eight and twelve weeks.

Holt gives the average duration of the disease as eight to nine weeks, while in the more severe cases, especially during the winter months, it may be prolonged to three or four months.

\section{DRUG TREATMENT}

Until the time I began the vaccine treatment, my best results had been obtained from the use of antipyrin combined with sodium bromid, given for one week, alternating with quinin bisulphate given for one week at a time, 2 grains of the antipyrin and 5 grains of the sodium bromid being given every four hours to a child of 3 to 6 years of age, while in infants from 6 months one-half grain of antipyrin and 2 grains of sodium bromid, the dose being slightly increased up to the third year. From 8 to 16 grains of quinin bisulphate per day were given alternate weeks, and all patients were told they should constantly wear a tight binder. This treatment is advocated by Kerley. Besides the above-mentioned treatment, malt and cod-liver oil were given during the spring and winter months. Although the cases improved steadily, the paroxysms decreasing in severity and number, the vomiting becoming less, under the use of these therapeutic agents, even the mild cases lasted from seven to twelve weeks and the severe cases longer.

\section{VACCINE TREATMLENT}

Thirty-three cases of whooping-cough were treated with the pertussis vaccine, and in all the effect of the vaccine was to diminish markedly the number and severity of the paroxysms and the amount of vomiting.

Absolutely no untoward effects from the use of the vaccine were noted. There were no complications in the cases in which the vaccine was used. No abscess formation, or even slight temporary inflammation or swelling at the site of the injection, and no general constitutional symptoms occurred. The longest time any of the children coughed was twelve weeks and four days. The longest time any child coughed after it was put under vaccine treatment was nine weeks and one day, the average length of time being four and one-half weeks. The injections were given every two or three days in most of the severe cases, and in the very severe cases every day for a few days, until the symptoms were relieved; the milder cases did not receive the vaccine so often nor so much at a time.

In giving the vaccine I was guided more by the severity of the disease than by the age of the child. The youngest child treated was 1 month old and the oldest was 6 years. Most of the children were from 
6 months to 3 years of age. The dose of the vaccine varied according to the number and severity of the paroxysms, from twenty million bacteria in the mild cases to sixty million in the severe cases.

The cases that were seen early in the attack, before the paroxysms had attained their height, seemed to respond more quickly to treatment and their course was shorter. In all cases, however, after one to three injections, the number and severity of the paroxysms was markedly lessened.

Some children seemed to respond better to treatment than others, and I attribute this to the fact that the dosage was given irrespective of the age; therefore, the younger children got a larger dose proportionately, and as a rule these latter were the ones that responded most quickly to the vaccine and had the shortest attacks after treatment was begun. This fact is important, since (heretofore) these young babies are so apt to have pneumonia complicating or accompanying pertussis, with fatal results.

It was found that the children did better when the vaccine was given in moderately large doses at frequent intervals of one or two days. A good example of this is Case 30, a child 14 months of age, which received $220,000,000$ bacteria or about forty million at a dose, about every two days for two weeks. This child had been coughing and vomiting for two weeks and was cured in two weeks, the vomiting having stopped on the ninth day after treatment was begun. Another very severe case was Case 31 , a child a year old that had from twenty to twenty-four paroxysms during the day and as many or more at night, with a great deal of vomiting. This child had been coughing for six weeks when it came for treatment. Forty million bacteria were given about every three days, $320,000,000$ in all, in four weeks, the time it took to effect a cure. Case 32 is a somewhat similar case, although an older child with paroxysms not so frequent; it got the vaccine every two days for three doses and then for every three days.

Case 20 was put on the vaccine at once and was ill for only two weeks and one day. Only sixty million bacteria were given, in three doses, but the child was only 7 months old.

The pertussis vaccine, at my suggestion, is now being put up in bulbs of fifty million to the c.c., and I believe the results with this more concentrated vaccine and the larger dosage ought to give considerably better results than I obtained, since in a number of my severe cases I found that forty million to sixty million bacteria at each injection were necessary to control the paroxysms and bring relief, and my opinion was confirmed that larger doses should be given and would effect a more rapid cure. The correct dosage for the mild cases is fifty million bacteria given every other day, while in the severe cases this amount should be 


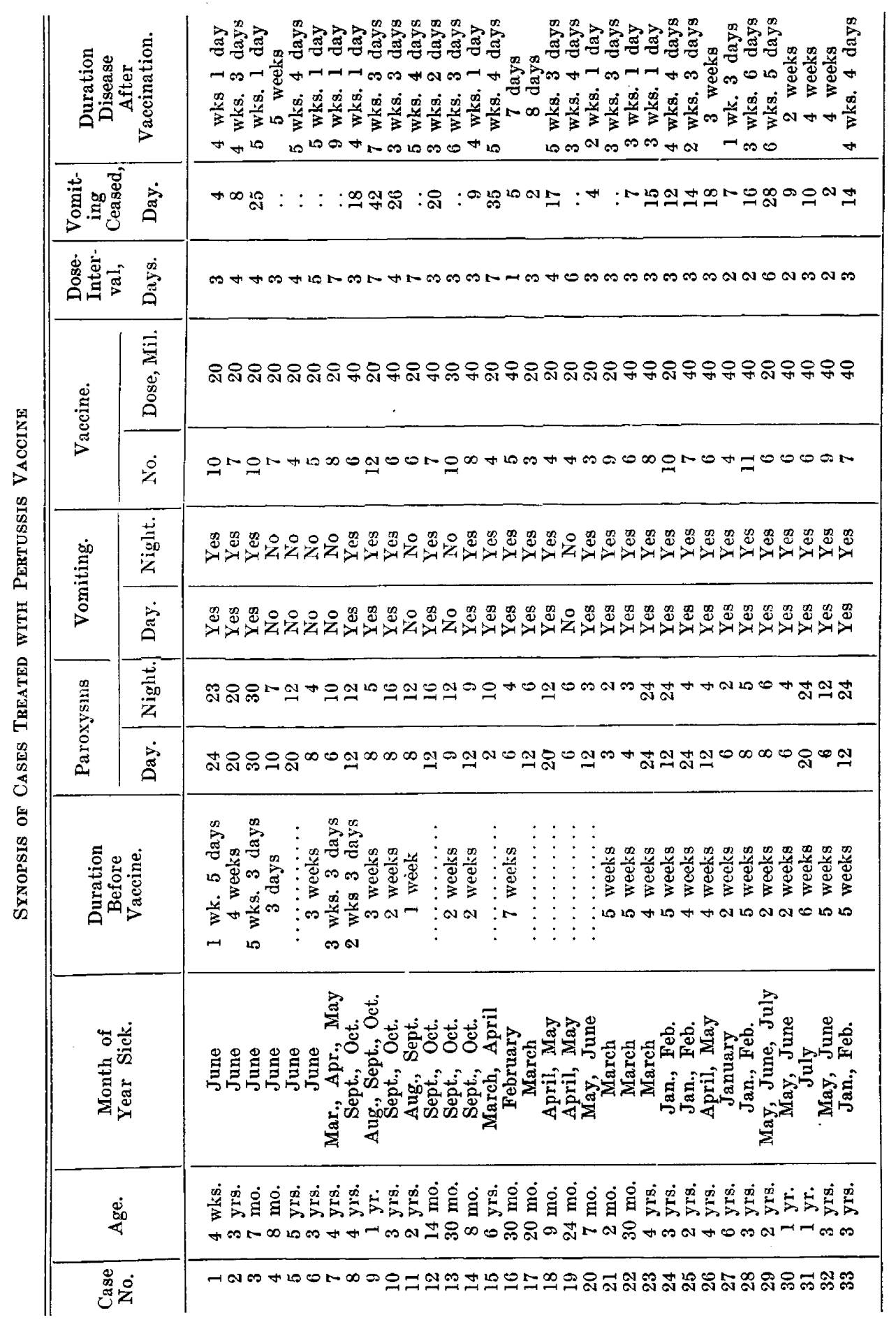


given every day, or one hundred million every other day. The vaccine is given under antiseptic precautions, subcutaneously, with the ordinary glass syringe, the injection being given in the abdomen or buttocks.

\section{PROPFYLAXIS}

A very interesting fact is that prophylactic treatment was instituted by giving immunizing doses of pertussis vaccine to children in a family in which one of the children was under treatment for whooping-cough. These children were watched over a period of two months, and although they had never had whooping-cough and were constantly exposed to the disease, did not contract it. It would seem, then, that the vaccine confers immunity to the child injected with small doses. One child of $\mathbf{5}$ years was given four injections of twenty million bacteria each, over a period of one month; another in the same family, 3 years of age, got nine injections of twenty million each, over a period of one month; neither child developed pertussis.

Ladd $^{4}$ reports nine cases of pertussis which he treated with vaceine, beginning with rather small doses and running up to twenty million, and in four cases to forty million bacteria at a dose, to babies 9 months of age. A minimum interval of five days was allowed between the injections, but in some cases the interval was lengthened to ten days or two weeks or longer. As a result of his investigation he concludes that in another series of cases he would give larger doses at shorter intervals.

When we consider how many of these cases of whooping-cough drag on for weeks or months and how many cases in infants terminate fatally from complications-since in the year 1908 in the registration area of the United States there were 4,969 deaths from whooping-cough, or eleven out of every 100,000 of population, practically the same number as died from measles and nearly as many as die from scarlet fever-it is not too much to say that the vaccine treatment of this disease should ever be in our minds, and should be given a fair and thorough trial and should also be given as a prophylactic measure to immunize children exposed.

Since writing this paper an article $\mathrm{e}^{5}$ has come to my notice. Three patients of the Boston City Hospital died of uncomplicated whoopingcough. An examination of their tracheas and lungs was made by Mallory and Horner, and it was found that these cases presented lesions which involved the ciliated epithelium lining the trachea and bronchi and which appear to be peculiar to this disease.

These observers found large numbers of minute bacteria between the cilia of many of the cells lining the trachea. This microorganism in

4. Ladd: Arch. Pediat., August, 1912.

5. Mallory and Horner: Jour. Med. Research, 1912, xxvii, No. 2, p. 115. 
most instances extended to the base of the cilia, the long axis extending in the direction of that of the cilia.

Masses of bacteria similar to those between the cilia were found in the secretions of the trachea and bronchi.

The organism found was a Gram-negative, minute, ovoid bacillus, which suggests strongly the bacillus discovered by Bordet and Gengou in 1900 and afterwards in 1906 obtained in pure culture. They are probably an identical organism. The above-named observers believe this organism to be the cause of whooping cough.

From these studies of Mallory and Horner it would seem that the action of the bacilli in the respiratory tract is apparently almost purely mechanical, because the presence of large numbers of these microorganisms between the cilia interferes with their action and checks the normal expulsion of secretion. These bacteria also cause irritation, and this in turn brings about coughing and the characteristic whoop or spasm.

104 West Seventy-Sixth Street. 